\title{
Synchronization of ice core records via atmospheric gases
}

\author{
T. Blunier ${ }^{1}$, R. Spahni ${ }^{1}$, J.-M. Barnola ${ }^{2}$, J. Chappellaz ${ }^{2}$, L. Loulergue ${ }^{2}$, and J. Schwander ${ }^{1}$ \\ ${ }^{1}$ Climate and Environmental Physics, Physics Institute, University of Bern, Sidlerstrasse 5, 3012 Bern, Switzerland \\ ${ }^{2}$ Laboratoire de Glaciologie et Géophysique de l'Environnement (LGGE), CNRS-UJF, 54 rue Molière, BP96 38402 Saint \\ Martin d'Heres Cedex, France
}

Received: 12 January 2007 - Published in Clim. Past Discuss.: 15 February 2007

Revised: 14 May 2007 - Accepted: 1 June 2007 - Published: 18 June 2007

\begin{abstract}
To interpret new high resolution climate records it becomes more and more important to know about the succession of climate events. Such knowledge is hard to get especially when dealing with different types of climate archives. Even for ice cores a direct synchronization between ice cores from Greenland and Antarctica has not been possible so far due to the lack of time markers occurring in both hemispheres. Fortunately, variations in the time series of global gas records can be used as indirect time markers. Here we discuss in detail the steps that are necessary to synchronize ice cores via global gas records exemplified on the synchronization of the EPICA ice core from Dronning Maud Land to a Greenland record from North GRIP.
\end{abstract}

\section{Introduction}

In-depth understanding of the climate system depends on knowledge of the succession of climate events. This knowledge is jeopardized by the lack of absolute ages in climate archives. However, the necessity of absolute ages is only prerequisite when comparing climate records from paleo archives to absolutely dated records like orbital parameters; else properly synchronized records are sufficient. Ice cores from the same hemisphere can be linked via volcanic eruptions; e.g. a reliable relative dating between most Antarctic ice cores has been established (Ruth et al., 2007). Linking ice cores between hemispheres is trickier. So far no volcanic layers beyond the historic era have been found in ice cores from both hemispheres which undoubtedly stem from the same eruption. One reliable age marker found in Greenland and Antarctic ice cores is the characteristic ${ }^{10} \mathrm{Be}$ double peak which corresponds to the Laschamp event at $40.4 \pm 2 \mathrm{kyr}$ BP (Guillou et al., 2004; Raisbeck et al., 2007). Away from

Correspondence to: T. Blunier

(blunier@climate.unibe.ch) this synchronization point the time scales between Greenland and Antarctic ice cores diverge (Parrenin et al., 2007; Ruth et al., 2007). The time scales can be linked via global gas parameters. Here the complication is that the age of the gas occluded in the ice is not identical to the age of the surrounding ice. This age difference ( $\Delta$ age) is a result of the gas being occluded not on top of the ice sheet but in a depth of roughly $100 \mathrm{~m}$ below surface where the ice already has a significant age in the range of a few hundred up to a few thousand years. $\Delta$ age can be calculated reliably for present day conditions (see for instance Blunier and Schwander, 2000) with a firn densification model. Here we discuss the procedure to synchronize ice cores; i.e. the EPICA Dronning Maud Land (EDML) core and the Greenland NGRIP core (EPICA community members, 2006). The ${ }^{10} \mathrm{Be}$ peak can be used to examine the reliability of the synchronization. On the other hand the ${ }^{10} \mathrm{Be}$ peak can be used to improve the $\Delta$ age calculation with the help of the $\Delta$ age model. This road is taken in the manuscript by Loulergue et al. (2007).

\section{Global gas records}

In principle any atmospheric gas record showing global variations can be used to synchronize ice cores from the two hemispheres. It is important that the lifetime of the gas is longer than the exchange time between the hemispheres to assure that variations in the atmospheric concentration occurring in one hemisphere have a significant imprint on the atmospheric concentration in the other hemisphere. Another requirement is reliable measurements. From the lifetime point of view $\mathrm{CO}_{2}$ and $\mathrm{N}_{2} \mathrm{O}$ are suitable for synchronization. However, $\mathrm{CO}_{2}$ can not be measured reliably in Greenland ice cores potentially due to chemical reactions in the ice leading to too high $\mathrm{CO}_{2}$ concentrations (Anklin et al., 1997; Stauffer et al., 2003). $\mathrm{N}_{2} \mathrm{O}$ although showing millennial scale variations can not be used since in Antarctic and Greenland ice

Published by Copernicus Publications on behalf of the European Geosciences Union. 


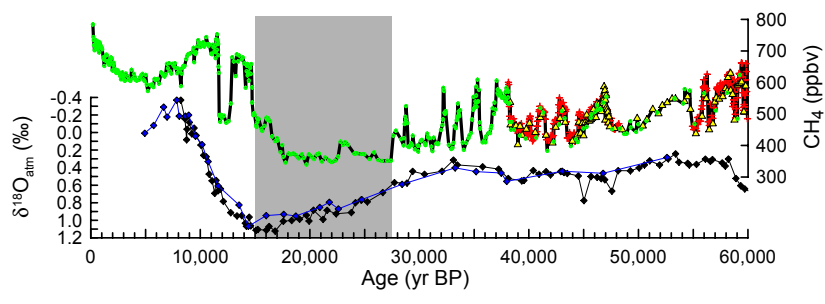

Fig. 1. Top: $\mathrm{CH}_{4}$ records used for the composite. Green Dots: GRIP; Yellow Triangles GISP2 (Blunier and Brook, 2001). Red Crosses: NGRIP (Flückiger et al., 2004). The synchronization period starts at $55 \mathrm{kyr}$ BP. The NGRIP data before $55 \mathrm{kyr}$ BP were used to match the GISP2 data correctly on the NGRIP time scale. The grey area marks the period where the synchronization via $\mathrm{CH}_{4}$ has its largest uncertainty. Bottom: $\delta^{18} \mathrm{O}$ of atmospheric $\mathrm{O}_{2}$ from GRIP (Blue diamonds) and GISP2 (Black diamonds) (Fuchs and Leuenberger, 1996; Sowers et al., 1989). All the records are plotted on the NGRIP time scale.

artefacts occur preferentially where the dust content is high (Flückiger et al., 2004).

$\delta^{18} \mathrm{O}$ of atmospheric $\mathrm{O}_{2}\left(\delta^{18} \mathrm{O}_{\mathrm{atm}}\right)$ and $\mathrm{CH}_{4}$ have been used in the past to synchronize ice cores (e.g. Bender et al., 1994a; Blunier and Brook, 2001; Blunier et al., 1998). $\delta^{18} \mathrm{O}_{\mathrm{atm}}$ is linked to the $\delta^{18} \mathrm{O}$ of seawater by biology. The atmospheric turn over time is on the order of 1000 years. Therefore $\delta^{18} \mathrm{O}$ of $\mathrm{O}_{2}$ shows only slow variations. Due to the long atmospheric lifetime there is no measurable pole to pole gradient in $\delta^{18} \mathrm{O}_{\mathrm{atm}}$ (Bender et al., 1994b).

The lifetime of $\mathrm{CH}_{4}$ is much shorter than for $\delta^{18} \mathrm{O}_{\mathrm{atm}}$, namely only on the order of 10 years. The advantage of the short lifetime is that changes in the production or destruction rate of methane have a large almost immediate impact on the atmospheric $\mathrm{CH}_{4}$ concentration. On the other hand the lifetime is only about ten times bigger than the atmospheric exchange time, resulting in a pole to pole gradient of a few per cent. Since $\mathrm{CH}_{4}$ shows large variations in a short time over Dansgaard-Oeschger (DO) events it is especially suited for a precise synchronization of these events.

Unfortunately, the $\mathrm{CH}_{4}$ time series lacks larger variations during the critical period preceding the last termination. Here the synchronization via $\mathrm{CH}_{4}$ has its largest uncertainty. $\delta^{18} \mathrm{O}_{\mathrm{atm}}$ has the potential to improve the synchronization. Between the last larger $\mathrm{CH}_{4}$ variation around $28 \mathrm{kyr} \mathrm{BP}$ (corresponding to DO 3) and the Last Glacial-Bølling transition $\delta^{18} \mathrm{O}_{\text {atm }}$ increases by about $0.5 \%$. The accuracy of a $\delta^{18} \mathrm{O}_{\text {atm }}$ of \pm 0.05 to $\pm 0.08 \%$ o (Fuchs and Leuenberger, 1996; Sowers and Bender, 1995) together with the lack of a pole to pole gradient should allow a firm synchronization over this time period. However, the quality of the data is not good enough to make an accurate synchronization. We compare $\delta^{18} \mathrm{O}_{\mathrm{atm}}$ from the GRIP and GISP2 cores. These two Greenland ice cores can be synchronized reliably via the isotopic signal of $\mathrm{H}_{2} \mathrm{O}$ (Johnsen et al., 2001). The $\Delta$ age of the two cores (see below) is almost identical and the uncertainty in the relative gas age is on the order of a few hundred years at most. Figure 1 shows the two $\delta^{18} \mathrm{O}_{\text {atm }}$ records on the same time scale. The two records differ by more than what would be expected from the uncertainty of the measurements. A reliable synchronization on the century scale with $\delta^{18} \mathrm{O}_{\text {atm }}$ will only be possible when the samples are remeasured. High precision measurements of $\delta^{18} \mathrm{O}_{\mathrm{atm}}$ are challenging and should be performed at the same time in the same laboratory. For now the atmospheric $\mathrm{CH}_{4}$ record is still the best choice to obtain a good synchronization of Greenland and Antarctic ice cores.

\section{Composite Greenland $\mathrm{CH}_{4}$ record}

At this time no complete high resolution Greenland $\mathrm{CH}_{4}$ record exists from a single ice core covering the time period between $55 \mathrm{kyr} \mathrm{BP}$ and today. Therefore we built a composite record based on the GRIP, NGRIP, and GISP2 $\mathrm{CH}_{4}$ data. This composite is the basis for the synchronization between Greenland and Antarctic ice cores. The highest resolution record is from NGRIP. Unfortunately this record covers, so far, only the period 48 to $38 \mathrm{kyr}$ BP (Flückiger et al., 2004). The entire time period is covered by the GRIP record but there are times when the resolution is relatively low, in particular before $38 \mathrm{kyr}$ BP (Blunier and Brook, 2001). Therefore we complement the GRIP and NGRIP record by GISP2 data before $38 \mathrm{kyr}$ (Table 1 ).

The time scale for the composite is the layer counted NGRIP time scale GICC05 (Andersen et al., 2006; Rasmussen et al., 2006). Before $41 \mathrm{kyr}$ BP the counted time scale was extended with the model time scale ss09sea (Andersen et al., 2004). For this purpose ss09sea was shifted by $300 \mathrm{yr}$ to younger ages. Huber et al. (2006) found from the concomitant signal of rapid temperature variations in the $\delta^{15} \mathrm{~N}$ of $\mathrm{N}_{2}$ that, for NGRIP, the modelled $\Delta$ age is too small. By decreasing the accumulation rate for the model calculation by $20 \%$ they obtain an optimal fit of the model $\Delta$ age for the time period where $\mathrm{CH}_{4}$ data for NGRIP exist. The GRIP $\mathrm{CH}_{4}$ data was assigned a NGRIP gas age interpolating between match points between the GRIP and NGRIP ice cores (Rasmussen et al., 2006, 2007). Note that no new $\Delta$ age is calculated. The original GRIP $\Delta$ age is projected on the NGRIP time scale. For GISP2 we use a different approach. The GISP2 $\mathrm{CH}_{4}$ data was matched directly on the existing NGRIP $\mathrm{CH}_{4}$ data before $55 \mathrm{kyr}$ BP (Huber et al., 2006) and after $48 \mathrm{kyr}$ BP. GISP2 $\mathrm{CH}_{4}$ data in the gap of the NGRIP data was assigned a NGRIP age by interpolation. The resulting Greenland composite record is shown in Fig. 1. No discrepancies between the $\mathrm{CH}_{4}$ data from the three ice cores are found.

\section{Matching $\mathrm{CH}_{4}$ records}

The EDML $\mathrm{CH}_{4}$-record has a lower resolution and covers a shorter time span than the Greenland composite. Therefore we match the EDML record on the Greenland composite 
Table 1. $\mathrm{CH}_{4}$ data for the Greenland composite.

\begin{tabular}{lllll}
\hline Core & Gasage interval*(kyr BP) & $\begin{array}{l}\text { Depth interval } \\
(\mathrm{m})\end{array}$ & Samples(\#) & Resolution(yr) \\
\hline NGRIP & 38 122-48 215 & $2085.1-2249.5$ & 164 & $63 \pm 26$ \\
NGRIP & $54922-$ NA & $2358.9-2463.5$ & 125 & $67 \pm 45$ \\
GRIP & $10128-59257$ & $1529.6-2472.8$ & 276 & $179 \pm 203$ \\
& $10128-38000$ & $1529.6-2205.9$ & 223 & $126 \pm 103$ \\
& $38000-59257$ & $1529.6-2472.8$ & 53 & $408 \pm 329$ \\
GISP2 & $38412-60086$ & $2205.9-2511.9$ & 145 & $236 \pm 214$ \\
\hline
\end{tabular}

\footnotetext{
* Ages are given on the layer counted NGRIP time scale GICC05 (Andersen et al., 2006; Rasmussen et al., 2006). Before 41 ky BP the model time scale ss09sea (Andersen et al., 2004) is fitted to the counted time scale.

** Depths are original depth from the individual ice cores.
}

record. We do this using a Monte Carlo method, which searches for a maximal correlation between the records (Schwander et al., 1997). The NGRIP reference record ( $a$ ) has data points $a\left(t_{i}\right), i \in\left[1 . . n_{a}\right]$ where $\mathrm{t}_{i}$ is the gas age of a data point. First the EDML $\mathrm{CH}_{4}$ record (b) is preliminarily matched to the composite Greenland record by match points at the fast transitions. The EDML record consists of values $\mathrm{b}\left(\mathrm{t}_{j}\right), j \in\left[1 . . n_{b}\right]$. The Monte Carlo program then improves the preliminary time scale. The process is as follows: A subset of $\ell \mathrm{CH}_{4}$ values from EDML with age $\mathrm{t}_{k}(k \in[1 . . \ell])$ is chosen. The program assigns a new age $t n_{k}=t_{k}+\Delta t_{k}$ to these data points where $\Delta t_{k}$ is chosen randomly within some limits. The drawing of new ages $\operatorname{tn}_{k}$ is repeated for 2000 times. The best correlation between sequences of $\mathrm{k}$ shifted methane values and the reference record is stored: $\operatorname{maxcorr}\left(b\left(t n_{k}\right), a^{\prime}\left(t n_{k}\right)\right) k \in[j . . j+\ell-1] ; j \in\left[1 . . n_{b}-\ell+l\right]$. Values $\mathrm{a}^{\prime}$ of the reference record at times $\operatorname{tn}_{k}$ are interpolated linearly from the original record. The matching procedure is started with the subrecord window placed at one end of the methane record. The window is then shifted by one methane data point, and the random variations are repeated again keeping the first point fixed with the best tn value resulting from the previous window position. The window is shifted until it reaches the other end of the record. Values $\Delta t_{k}$ are drawn randomly in discrete 25 year steps. We limit $\Delta t_{k}$ to $\pm 1500 \mathrm{yr}$ to hinder that the program assigns peaks to the $\mathrm{CH}_{4}$ variation before or after the one it belongs to. Further $\Delta t_{k}$ is chosen so that the relative "error" of the initial preliminary time scale is no bigger than $80 \%$. New times $\operatorname{tn}_{k}$ are discarded if they change the succession of data points. Windows of $\ell$ values with variation smaller than $20 \mathrm{ppbv}$ are not considered in order to avoid correlation of very small signals. It is possible to obtain a very high correlation with signals of very different amplitudes. For instance an identical but ten times smaller signal will have a correlation of 1 but is of course completely meaningless. To omit this situation the slope of the regression $b\left(t_{k}\right)$ versus $\mathrm{a}^{\prime}\left(\operatorname{tn}_{k}\right)$ has to be between 0.9 and 1.1 for a valid draw. For a solution to be considered valid the correlation coefficient has to be at least 0.85 . It turned out that the method is quite insensitive toward the direction in which the window is moved through the record. The whole procedure is repeated 20 times for each direction. For each methane data point we have calculate mean and standard deviation of the $\Delta t_{k}$ values meeting the conditions above. The standard deviation gives us a measure of how accurate the match is relatively from one point of the record to another. It does, however, not give us an absolute uncertainty since this parameter depends on the number of runs performed. With the $\mathrm{CH}_{4}$ record of the Greenland composite and EDML on the same time scale we now calculate ice ages for the two sites applying $\Delta$ age.

\section{Error estimate}

Three factors determine the uncertainty of the synchronization for the ice time scale. These are the uncertainties of $\Delta$ age for the two ice cores and the uncertainty of the match of the $\mathrm{CH}_{4}$ records. The latter is mainly determined by the resolution of the records. However, also the uncertainty of the concentration and the interhemispheric gradient of the $\mathrm{CH}_{4}$ records are of some importance. We note, however, that this difference is smallest during the cold periods of the glacial (Dällenbach et al., 2000).

A firn densification model is used to calculate $\Delta$ age. $\Delta$ age is dependent on the local temperature and the accumulation rate (Fig. 2). Our model (Schwander et al., 1997) includes the heat transport in the firn but neglects heat diffusion from the bedrock (Goujon et al., 2003). Including the latter would lead to an increased temperature in the firn implicating a slightly smaller $\Delta$ age. However, the difference is small and since all calculations were made with the same model this effect cancels out to some degree. Since the model is dynamic also the underlying time scale has an, although small, influence on $\Delta$ age. The firn densification model proved to work very well under present day conditions. The model is capable to simulate the occlusion process 


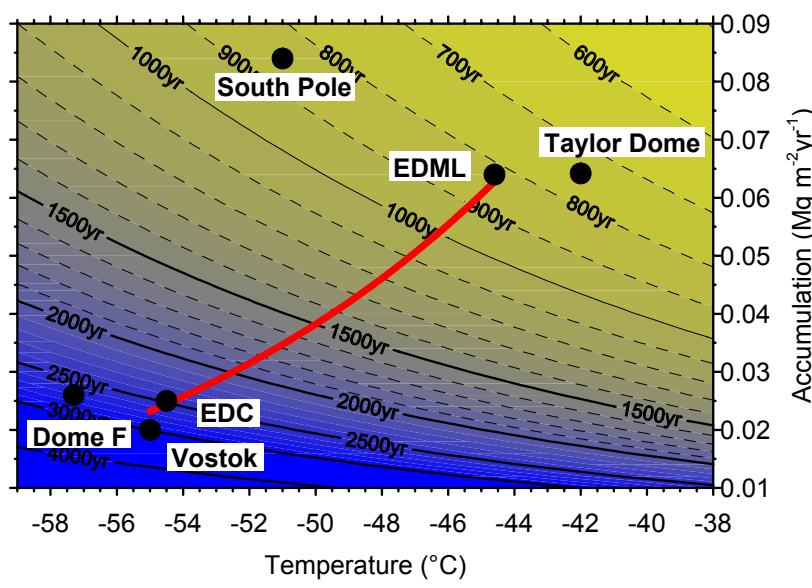

Fig. 2. $\Delta$ age over the range of temperature and accumulation rate of the EDML record back to $60 \mathrm{kyr}$ BP. $\triangle$ age was calculated with a steady state version of our model. The red line shows the temperature and accumulation range used for the $\Delta$ age calculation. The black dots show present conditions for several Antarctic ice cores.

under very different conditions ranging from accumulation rates as low as 0.02 to over $0.5 \mathrm{Mg} \mathrm{m}^{-2} \mathrm{yr}^{-1}$ and temperatures from $-58^{\circ}$ to $-13^{\circ} \mathrm{C}$. Both NGRIP and EDML conditions for the last $60 \mathrm{kyr} \mathrm{BP}$ are fully within that range. The uncertainty of the $\Delta$ age calculation originates mainly from the uncertainty of the input parameters. In Fig. 3 we show the range of $\Delta$ age for EDML, GRIP (after $38 \mathrm{kyr} \mathrm{BP}$ ) and NGRIP (before $38 \mathrm{kyr}$ BP) allowing a $25 \%$ change in the accumulation rate. The effect on $\Delta$ age is about equivalent to a $2 \%$ change in absolute temperature. $\Delta$ age for NGRIP is larger than for GRIP mainly due to the lower accumulation rate at NGRIP relative to GRIP.

For low accumulation sites but also for EDML the gravitational enrichment of $\delta^{15} \mathrm{~N}$ in the firn column indicates that the glacial diffusive column height decreased relative to the present observations. As opposed to these observations densification models predict an increase in the diffusive column height under glacial conditions (see Landais et al., 2006, for a recent review). Landais et al. (2006) propose a solution which would make EDML $\Delta$ age at the last glacial maximum $300 \mathrm{yr}$ larger than in our calculations. This is slightly bigger than the effect we calculate for a $25 \%$ reduction in accumulation rate. However, other explanations are possible and a definite explanation for the discrepancy between densification models and $\delta^{15} \mathrm{~N}$ data is pending.

Here we used two synchronization methods to assess the temporal coupling of both hemispheres (EPICA community members, 2006). In the first method the high resolution Greenland composite $\mathrm{CH}_{4}$ record has been matched with the EDML $\mathrm{CH}_{4}$ record making use of the global signal in atmospheric $\mathrm{CH}_{4}$ changes. For NGRIP we use the $\Delta$ age confirmed by the synchronous effect of a fast temperature change in the ice and the gas record. Using the NGRIP age scale

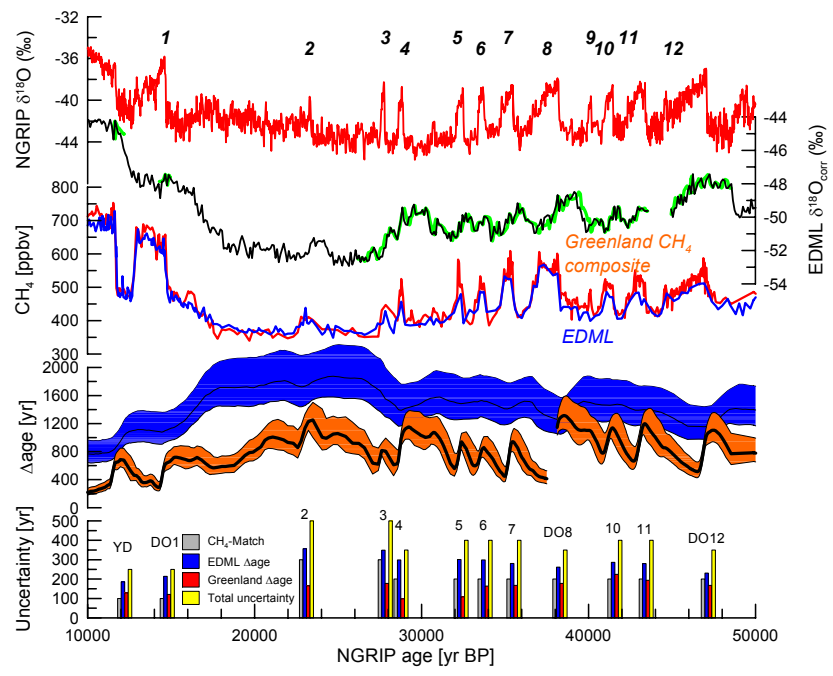

Fig. 3. From top to bottom: NGRIP $\delta^{18} \mathrm{O}$ record, a proxy for the local temperature (Andersen et al., 2004). $\delta^{18} \mathrm{O}$ from EDML corrected for sea level and upstream correction (see EPICA community members, 2006, for details). This record is synchronized to the NGRIP record: The result of two approaches is shown: 1) EDML was synchronized via methane records from NGRIP and EDML (black line); 2) The EDML methane record was directly linked to the $\delta^{18} \mathrm{O}$ of NGRIP (green line), see text for details. $\mathrm{CH}_{4}$ records for Greenland (red) and EDML (blue). $\triangle$ age with uncertainty corresponding to a $25 \%$ change in the accumulation rate. The effect is about similar to a $2 \%$ change in absolute temperature. Blue for EDML and red for the Greenland composite, respectively. Before $38 \mathrm{kyr}$ BP the synchronization is based on NGRIP data and the NGRIP $\triangle$ age is shown. After $38 \mathrm{kyr}$ the synchronization is based on GRIP $\mathrm{CH}_{4}$ data and the GRIP $\Delta$ age is shown. Uncertainty of the synchronization: The grey bar represents the uncertainty of the $\mathrm{CH}_{4}$ synchronization. Blue and Red bars show the uncertainty of $\Delta$ age assuming a $25 \%$ change in accumulation for EDML and the Greenland composite, respectively. The three components are added in quadrature to a total uncertainty for the synchronization of the ice records (yellow bar).

and the $\Delta$ age at both sites we arrive at a synchronized time scale for the Greenland and Antarctic $\delta^{18} \mathrm{O}$ records. The result of this approach (EPICA community members, 2006) is shown in Fig. 3. For this approach we estimate the total synchronization uncertainty at the start of DO events adding in quadrature the uncertainties for the synchronization of the $\mathrm{CH}_{4}$ records and the two $\triangle$ ages for EDML and the Greenland composite. Based on the resolution and the structure of the $\mathrm{CH}_{4}$ records we estimate that the uncertainty for the $\mathrm{CH}_{4}$ synchronization is small over the Younger Dryas (about 100 years) and on the order of 200 years for most DO events. For DO 2 and DO 3 the error is larger, about 300 years. The total synchronization error adds to $250 \mathrm{yr}$ for the YD, $500 \mathrm{yr}$ for DO 2 and DO 3, and about $400 \mathrm{yr}$ for other DO events. In between the rapid $\mathrm{CH}_{4}$ changes the synchronization error may be larger. We estimate about 800 years where small $\mathrm{CH}_{4}$ variations are found. 
One $\Delta$ age uncertainty can be omitted by matching the Antarctic $\mathrm{CH}_{4}$ record directly to the Greenland temperature record. It has been shown that rapid changes in temperature and $\mathrm{CH}_{4}$ concentration at the beginning of DO events are concomitant or with only a small time lag of $25-70 \mathrm{yr}$ (Huber et al., 2006). However, this is not possible for all times. Although the two signals are very similar there are differences in the structure of the temperature and the $\mathrm{CH}_{4}$ records. This approach gives, where applicable, identical solutions with the first approach (Fig. 3).

Since variations of the Greenland temperature and the $\mathrm{CH}_{4}$ record are so similar a comparison of the EDML $\delta^{18} \mathrm{O}$ record to its $\mathrm{CH}_{4}$ record is synonymous to a (low resolution) comparison to the Greenland temperature. This third method avoids again the calculation of $\Delta$ age for the Greenland records.

As pointed out above, method 2 and 3 are not applicable for all temporal changes in the $\mathrm{CH}_{4}$ record due to the different nature of the $\mathrm{CH}_{4}$ and $\delta^{18} \mathrm{O}$ signal. Nevertheless, all three approaches give within the above mentioned uncertainties the same results in terms of succession of climate events between Greenland and Antarctic temperature variations.

An independent check of our $\mathrm{CH}_{4}$ synchronization of the $\delta^{18} \mathrm{O}$ records comes from the ${ }^{10} \mathrm{Be}$ peak at approximately $40.4 \pm 2$ kyr BP (Guillou et al., 2004). Here the direct synchronization of $\delta^{18} \mathrm{O}$ records using ${ }^{10} \mathrm{Be}$ (which is accurate to within \pm 200 years (Raisbeck et al., 2002)) and synchronization via the $\mathrm{CH}_{4}$ records involving the gas age/ice age difference agree within the synchronization uncertainties. In summary the $\mathrm{CH}_{4}$ synchronization allows a reliable comparison of millennial climate variations between the hemispheres. The quantification of the exact timing of peak warmth in Antarctica and rapid transitions in Greenland (EPICA community members, 2006) is generally better than 400 years (Fig. 3). Two of the rapid $\mathrm{CH}_{4}$ increases at $11.65 \pm 0.32$ and $14.64 \pm 0.35 \mathrm{kyr}$ BP (GICC05) were used as age markers for the EPICA Dome C time scale (EDC3) (see Parrenin et al., 2007 , for details).

\section{Conclusions}

While a direct synchronization of ice core records from the two hemispheres is pending, matching of gas records is currently the best tool to interpret the link of climate events in the two hemispheres. The quality of the synchronization depends on the quality of the gas records and their resolution but to a main portion on the ability to calculate $\Delta$ age. Climate conditions of the past for EDML and NGRIP are within the range of modern analogues for which the densification model is proven to work. However, the quality of the synchronization can be increased when direct observations of $\Delta$ age allow tuning the model for uncertainties of the input parameters. For Greenland such an improvement can be made over the $\delta^{15} \mathrm{~N}$ record reacting to drastic tem- perature changes (Huber et al., 2006). For Antarctica such an approach is with exceptions not possible. The ${ }^{10} \mathrm{Be}$ peak is a first possibility to constrain the densification model for EDML and EDC although not independently (Loulergue et al., 2007).

Acknowledgements. This work is a contribution to the European Project for Ice Coring in Antarctica (EPICA), a joint European Science Foundation/European Commission scientific programme, funded by the EU (EPICA-MIS) and by national contributions from Belgium, Denmark, France, Germany, Italy, the Netherlands, Norway, Sweden, Switzerland and the UK. The main logistic support was provided by IPEV and PNRA (at Dome C) and AWI (at Dronning Maud Land). This is EPICA publication no. 173.

Edited by: E. W. Wolff

\section{References}

Andersen, K. K., Azuma, N., Barnola, J. M., et al.: High-resolution record of Northern Hemisphere climate extending into the last interglacial period, Nature, 431, 147-151, 2004.

Andersen, K. K., Svensson, A., Johnsen, S. J., et al.: The Greenland Ice Core Chronology 2005, 15-42 kyr. Part 1: Constructing the time scale, Quat. Sci. Rev., 25, 3246-3257, 2006.

Anklin, M., Schwander, J., Stauffer, B., Tschumi, J., Fuchs, A., Barnola, J. M., and Raynaud, D.: $\mathrm{CO}_{2}$ record between 40 and 8 kyr B.P. from the Greenland Ice Core Project ice core, J. Geophys. Res., 102, 26 539-26 546, 1997.

Bender, M., Sowers, T., Dickson, M.-L., Orchardo, J., Grootes, P., Mayewski, P. A., and Meese, D. A.: Climate correlations between Greenland and Antarctica during the past 100,000 years, Nature, 372, 663-666, 1994a.

Bender, M., Sowers, T., and Labeyrie, L.: The Dole effect and its variations during the last 130,000 years as measured in the Vostok ice core, Global Biogeochem. Cycles, 8, 363-376, 1994b.

Blunier, T. and Brook, E. J.: Timing of millennial-scale climate change in Antarctica and Greenland during the last glacial period, Science, 291, 109-112, 2001.

Blunier, T., Chappellaz, J., Schwander, J., et al.: Asynchrony of Antarctic and Greenland climate change during the last glacial period, Nature, 394, 739-743, 1998.

Blunier, T. and Schwander, J.: Gas enclosure in ice: age difference and fractionation, in: Physics of ice core records, edited by: Hondoh, T., pp. 307-326, Hokkaido University Press, Sapporo, 2000.

Dällenbach, A., Blunier, T., Flückiger, J., Stauffer, B., Chappellaz, J., and Raynaud, D.: Changes in the atmospheric $\mathrm{CH}_{4}$ gradient between Greenland and Antarctica during the Last Glacial and the transition to the Holocene, Geophys. Res. Lett., 27, 10051008, 2000.

EPICA community members: One-to-one coupling of glacial climate variability in Greenland and Antarctica, Nature, 444, 196198, 2006.

Flückiger, J., Blunier, T., Stauffer, B., Chappellaz, M., Spahni, R., Kawamura, K., Schwander, J., Stocker, T. F., and Dahl-Jensen, D.: $\mathrm{N}_{2} \mathrm{O}$ and $\mathrm{CH}_{4}$ variations during the last glacial epoch: Insight into global processes, Global Biogeochem. Cycles, 18, GB1020, doi:1010.1029/2003GB002122, 2004. 
Fuchs, A. and Leuenberger, M.: $\delta^{18} \mathrm{O}$ of atmospheric oxygen measured on the GRIP ice core document stratigraphic disturbances in the lowest $10 \%$ of the core, Geophys. Res. Lett., 23, 10491052, 1996.

Goujon, C., Barnola, J.-M., and Ritz, C.: Modeling the densification of polar firn including heat diffusion: Application to closeoff characteristics and gas isotopic fractionation for Antarctica and Greenland sites, J. Geophys. Res., 108(D24), 4792, doi:10.1029/2002JD003319, 2003.

Guillou, H., Singer, B. S., Laj, C., Kissel, C., Scaillet, S., and Jicha, B. R.: On the age of the Laschamp geomagnetic excursion, Earth Planet. Sci. Lett., 227, 331-343, 2004.

Huber, C., Leuenberger, M., Spahni, R., Flückiger, J., Schwander, J., Stocker, T. F., Johnsen, S., Landals, A., and Jouzel, J.: Isotope calibrated Greenland temperature record over Marine Isotope Stage 3 and its relation to CH4, Earth Planet. Sci. Lett., 243, 504-519, 2006.

Johnsen, S. J., Dahl-Jensen, D., Gundestrup, N., Steffensen, J. P., Clausen, H. B., Miller, H., Masson-Delmotte, V., Sveinbjornsdottir, A. E., and White, J.: Oxygen isotope and palaeotemperature records from six Greenland ice-core stations: Camp Century, Dye-3, GRIP, GISP2, Renland and NorthGRIP, J. Quat. Sci., 16, 299-307, 2001.

Landais, A., Barnola, J. M., Kawamura, K., et al.: Firn-air $\delta^{15} \mathrm{~N}$ in modern polar sites and glacial-interglacial ice: a model-data mismatch during glacial periods in Antarctica?, Quat. Sci. Rev., 25, 49-62, 2006.

Loulergue, L., Parrenin, F., Blunier, T., Barnola, J.-M., Spahni, R., Schilt, A., Raisbeck, G., and Chappellaz, J.: New constraints on the gas age-ice age difference along the EPICA ice cores, 050 kyr, Clim. Past Discuss., 3, 435-467, 2007, http://www.clim-past-discuss.net/3/435/2007/.

Parrenin, F., Barnola, J.-M., Beer, J., et al.: The EDC agescale for the EPICA Dome C ice core, Clim. Past Discuss., 3, 575-606, 2007 , http://www.clim-past-discuss.net/3/575/2007/.

Raisbeck, G. M., Yiou, F., and Jouzel, J.: Cosmogenic ${ }^{10} \mathrm{Be}$ as a high resolution correlation tool for climate records, Geochimica Et Cosmochimica Acta, 66, A623-A623, 2002.
Raisbeck, G. M., Yiou, F., Jouzel, J., and Stocker, T. F.: Direct North-South synchronization of abrupt climate change record in ice cores using ${ }^{10} \mathrm{Be}$, Clim. Past Discuss., 3, 755-769, 2007, http://www.clim-past-discuss.net/3/755/2007/.

Rasmussen, S. O., Andersen, K. K., Svensson, A. M., Steffensen, J. P., Vinther, B. M., Clausen, H. B., Siggaard-Andersen, M.L., Johnsen, S. J., Larsen, L. B., Dahl-Jensen, D., Bigler, M., Röthlisberger, R., Fischer, H., Goto-Azuma, K., Hansson, M. E., and Ruth, U.: A new Greenland ice core chronology for the last glacial termination, J. Geophys. Res., 111, D06102, doi:10.1029/2005JD006079, 2006.

Rasmussen, S. O., Seierstad, I. K., Andersen, K. K., Bigler, M., and Johnsen, S. J.: Synchronization of the NGRIP, GRIP, and GISP2 ice cores across MIS 2 and palaeoclimatic implications, Quat. Sci. Rev., in press, 2007.

Ruth, U., Barnola, J.-M., Beer, J., et al.: "EDML1”: A chronology for the EDML ice core, Antarctica, over the last 150000 years, Clim. Past Discuss., 3, 549-574, 2007, http://www.clim-past-discuss.net/3/549/2007/.

Schwander, J., Sowers, T., Barnola, J.-M., Blunier, T., Malaizé, B., and Fuchs, A.: Age scale of the air in the summit ice: Implication for glacial-interglacial temperature change, J. Geophys. Res., 102, 19483-19494, 1997.

Sowers, T. and Bender, M.: Climate records covering the last deglaciation, Science, 269, 210-214, 1995.

Sowers, T. A., Bender, M. L., and Raynaud, D.: Elemental and isotopic composition of occluded $\mathrm{O}_{2}$ and $\mathrm{N}_{2}$ in polar ice, J. Geophys. Res., 94, 5137-5150, 1989.

Stauffer, B., Flückiger, J., Monnin, E., Nakazawa, T., and Aoki, S.: Discussion of the reliability of $\mathrm{CO}_{2}, \mathrm{CH}_{4}$ and $\mathrm{N}_{2} \mathrm{O}$ records from polar ice cores, in: Global scale climate and environment study through polar deep ice cores: Proceeding of the international symposium on Dome Fuji ice core and related topics, 2728 February 2001, Tokyo, edited by: Shoji, H. and Watanabe, O., pp. 139-152, National Institute of Polar Research, Tokyo, 2003. 